\title{
Diversity of meiofauna and free-living nematodes in hydrothermal vent mussel beds on the northern and southern East Pacific Rise
}

\author{
J.T.P. Copley*`, H.C. Flint*, T.J. Ferrero ${ }^{\dagger}$ and G.L. Van Dover ${ }^{\star}$ \\ *School of Ocean \& Earth Science, University of Southampton, European Way, Southampton, SO14 3ZH, UK. \\ ${ }^{\dagger}$ Natural History Museum, Cromwell Road, London, SW7 5BD, UK. ${ }^{2}$ Duke University Marine Laboratory, \\ Beaufort, NG 28516-9721, USA. `Corresponding author, e-mail: jtc@noc.soton.ac.uk
}

\begin{abstract}
The ecology and biogeography of meiofauna at deep-sea hydrothermal vents have historically received less attention than those of mega- and macrofauna. This study examines the composition of major meiofaunal taxa in beds of the mussel Bathymodiolus thermophilus at hydrothermal vents on the northern and southern East Pacific Rise (EPR) and presents the first comparison of species assemblages of the dominant taxon, the nematodes, among sites spanning 27 degrees of latitude. Meiofaunal samples were collected by submersible from three mussel beds at $9^{\circ} \mathrm{N}$ on the EPR and four mussel beds between 17 and $18^{\circ} \mathrm{S}$ in 1999. Estimated ages of the mussel beds at the time of sampling range from 4 to $>20$ years, enabling investigation of the influence of mussel bed age on meiofaunal assemblages. Overall, the meiofauna of the mussel beds was dominated by nematodes, with copepods constituting the second most abundant meiofaunal group. There was variation in the ratio of nematodes to copepods between sites, however, with copepods more abundant than nematodes in the youngest mussel beds. Apart from polychaete larvae, other meiofaunal groups were generally present at very low abundance $(<1 \%)$ in the samples and restricted in diversity to gastropod larvae, acari, foraminifera, ostracoda and turbellaria. Seventeen nematode species from 14 genera and 11 families were found in the samples, with no evidence of endemicity to hydrothermal vents at the generic level. Four genera present were not previously recorded at hydrothermal vents. Nematode species richness, species:genus ratios and abundances were low compared with other deep-sea habitats, though the ecological relevance of comparisons with soft-sediment benthos is discussed. Nematode assemblages exhibited high dominance by a few species, with one species of Thalassomonhystera most abundant at five of the seven vent sites. Multivariate analysis of nematode assemblages reveals similarities among sites that do not match geographical proximity. The youngest mussel beds were most similar to each other and exhibited lower species richness than other sites, consistent with colonization of mussel bed habitat by nematodes over time. Similarity in the composition of nematode assemblages among sites separated by $\sim 3000 \mathrm{~km}$ indicates that they lie within a single biogeographic province, consistent with that proposed for mussel bed macrofauna. At a generic level, samples exhibited some overlap with nematode assemblages at vents elsewhere on the EPR, on the Mid Atlantic Ridge and in the North Fiji Basin.
\end{abstract}

\section{INTRODUCTION}

More than 400 new morphological species of megaand macrofauna have been described from deep-sea hydrothermal vent communities since their discovery in the late 1970s (Van Dover et al., 2002). The taxonomic level of apparent endemicity in these faunas is typically high, often involving new genera, families and classes. Mega- and macrofauna at vents also usually exhibit high abundance, high dominance and low species richness compared with non-chemosynthetic deep-sea habitats (Tunnicliffe, 1991; Van Dover, 2002). The ecology of meiofauna at deepsea hydrothermal vents, however, has received much less attention than that of their larger counterparts. There have been taxonomic studies of some meiofaunal groups such as siphonostome copepods associated with vestimentiferan tubeworms (e.g. Humes, 1984), but only limited consideration of free-living nematodes and general ecological patterns in this size fraction, largely as a consequence of difficulties in reliably sampling vent meiofauna and the specialist effort required in their identification (Vanreusel et al., 1997).

The term meiofauna was introduced by Mare (1942) in the pages of this journal to describe benthic fauna 'of intermediate size'. The minimum size of meiofauna has been defined operationally by the sieves used to process samples; in the deep sea these have varied from $74 \mu \mathrm{m}$ (Wigley \& McIntyre, 1964) to $32 \mu \mathrm{m}$ (SCOR Working Group 76, 1994). Nematodes typically dominate the meiofauna of the softsediment deep-sea benthos, for example constituting $80 \%$ of metazoans on average in 19 studies reviewed by Soltwedel (2000), who also recognized a general increase in the relative abundance of this group with depth on continental slopes. Meiofaunal studies in deep-sea chemosynthetic environments hosted on soft sediments, such as cold seeps 


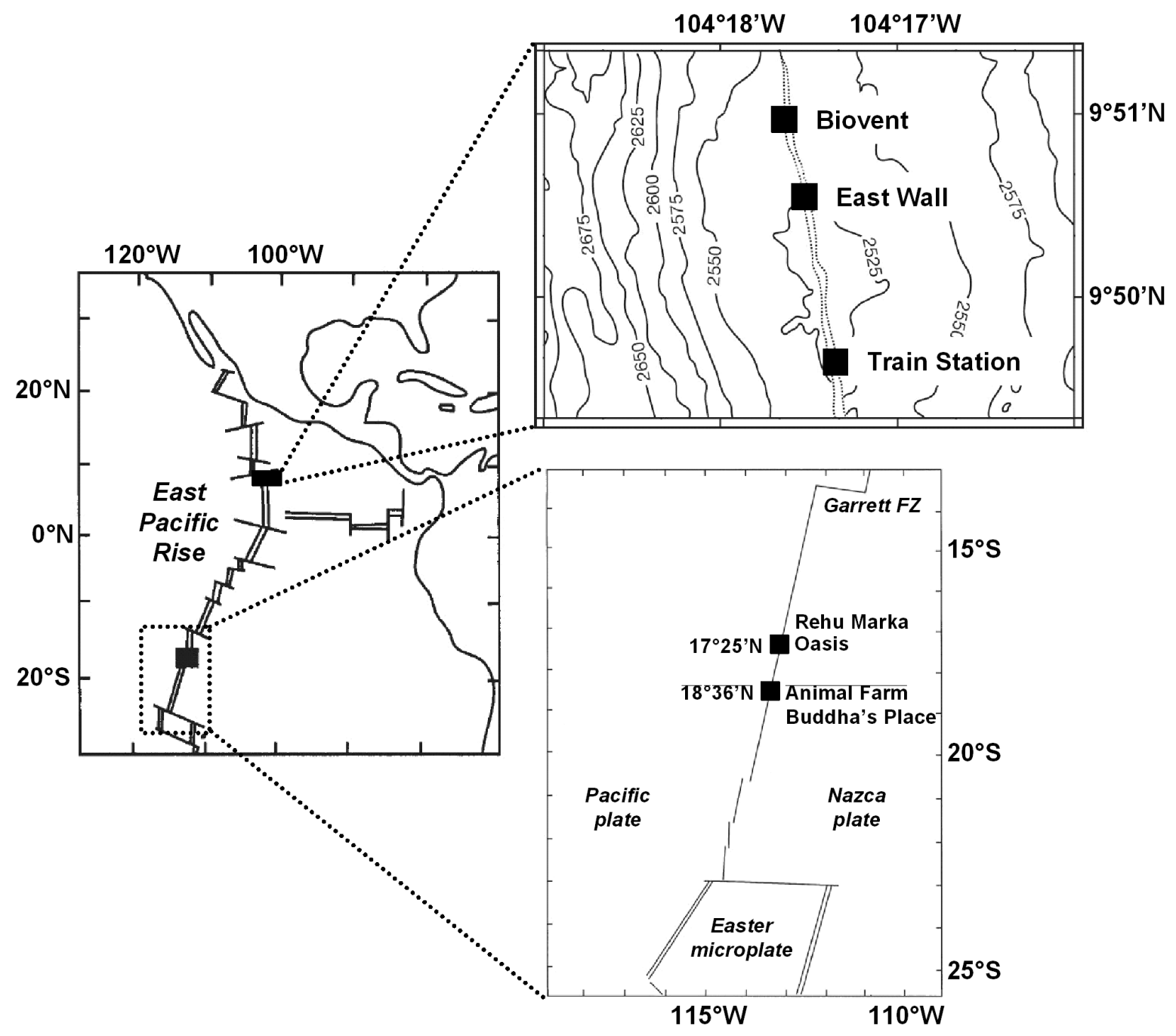

Figure 1. Location map of Bathymodiolus thermophilus mussel beds sampled on the East Pacific Rise (adapted from Van Dover, 2002 and Dreyer et al., 2005).

and mud volcanoes, have noted differences in abundance and composition compared with non-chemosynthetic areas nearby (Shirayama \& Ohta, 1990; Buck \& Barry, 1998; Soltwedel et al., 2005).

At deep-sea hydrothermal vents, Dinet et al. (1988) examined the meiofauna in samples from $21^{\circ} \mathrm{N}$ on the East Pacific Rise, Guaymas Basin and Explorer Ridge in the north-east Pacific, while Vanreusel et al. (1997) described the meiofaunal composition of samples from vents in the North Fiji Basin. More recently, Zekely et al. (2006a) have described the meiofauna of vent mussel beds at $11^{\circ} \mathrm{N}$ on the East Pacific Rise and $23^{\circ} \mathrm{N}$ on the Mid Atlantic Ridge. Overall diversity of meiofauna in these studies was lower than nonhydrothermal deep-sea areas and dominated by nematodes and copepods. Nematodes belonged to families (Dinet et al., 1988) and genera (Vanreusel et al., 1997; Zekely et al., 2006b) already known from non-vent habitats and exhibited high dominance by a few taxa. Dinet et al. (1988) also noted differences in the meiofaunal composition of different habitats associated with hydrothermal vents at $21^{\circ} \mathrm{N}$ on the East Pacific Rise (EPR), comparing washings of macrofauna (vestimentiferan tubeworms, alvinellid polychaetes and vesicomyid clams) with scoops of hydrothermal sediment.
Beds of Bathymodiolus mussels form discrete patches at hydrothermal vents in the Pacific and Atlantic, exhibiting similar physical structures across different settings and locations. As these mussel beds can be quantitatively sampled with relative ease, they have provided ecological units for comparisons of macrofaunal assemblages between sites (Van Dover \& Trask, 2000; Van Dover, 2002; Dorries \& Van Dover, 2003; Turnipseed et al., 2003; Van Dover, 2003; Dreyer et al., 2005). Zekely et al. (2006a) report nine species of nematode in mussel beds at $11^{\circ} \mathrm{N}$ on the EPR and seven species in a mussel bed on the Mid Atlantic Ridge (MAR), with no species but five genera in common between them. The meiofauna of vent mussel beds elsewhere on the northern and southern East Pacific Rise (NEPR and SEPR), however, have yet to be described and compared.

The hydrothermal setting of Bathymodiolus thermophilus beds on the EPR seldom results in temperature excursions greater than 10 to $15^{\circ} \mathrm{C}$ (Van Dover, 2002). Bed formation progresses from initial colonization to well-developed aggregations of adult mussels within $5 \mathrm{y}$, with beds typically persisting for 10 to $20 \mathrm{y}$ depending on fluctuations in local hydrothermal conditions. Comparisons of NEPR and SEPR mussel beds $\sim 3000 \mathrm{~km}$ apart indicate that their macrofauna 
Table 1. Summary of sample site locations and conditions (data from Van Dover, 2002, 2003).

\begin{tabular}{|c|c|c|c|c|c|c|}
\hline Site & Location & Depth (m) & $\begin{array}{c}\text { Date } \\
\text { sampled }\end{array}$ & $\begin{array}{l}\text { Alvin } \\
\text { dive no. }\end{array}$ & $\begin{array}{c}\text { Temperature above } \\
\text { ambient }\left({ }^{\circ} \mathrm{G}\right)\end{array}$ & $\begin{array}{c}\text { Estimated } \\
\text { age }(y)\end{array}$ \\
\hline NEPR & & & & & (ambient $\sim 2^{\circ} \mathrm{C}$ ) & \\
\hline Biovent & $9^{\circ} 50.992^{\prime} \mathrm{N} 104^{\circ} 17.592^{\prime} \mathrm{W}$ & 2494 & $18 / 11 / 99$ & 3490 & $2-4$ & $>8$ \\
\hline East Wall & $9^{\circ} 50.534^{\prime} \mathrm{N} 104^{\circ} 17.520^{\prime} \mathrm{W}$ & 2499 & $17 / 11 / 99$ & 3489 & $1-8$ & 4 \\
\hline Train Station & $9^{\circ} 49.645^{\prime} \mathrm{N} 104^{\circ} 17.357^{\prime} \mathrm{W}$ & 2491 & $16 / 11 / 99$ & 3488 & $2-5$ & 5 \\
\hline SEPR & & & & & $\left(\right.$ ambient $\left.\sim 1.7^{\circ} \mathrm{C}\right)$ & \\
\hline Rehu Marka & $17^{\circ} 24.940^{\prime} \mathrm{S} 113^{\circ} 12.190^{\prime} \mathrm{W}$ & 2581 & $23 / 02 / 99$ & 3362 & 8 & $10-16$ \\
\hline Oasis & $17^{\circ} 25.394 ' \mathrm{~S} 113^{\circ} 12.323^{\prime} \mathrm{W}$ & 2582 & $19 / 02 / 99$ & 3358 & 4.5 & 6 \\
\hline Animal Farm & $18^{\circ} 36.429^{\prime} \mathrm{S} 113^{\circ} 23.995^{\prime} \mathrm{W}$ & 2675 & $08 / 02 / 99$ & 3349 & 0.1 & $>20$ \\
\hline Buddha's Place & $18^{\circ} 40.416^{\prime} \mathrm{S} 113^{\circ} 24.867^{\prime} \mathrm{W}$ & 2690 & $09 / 02 / 99$ & 3350 & - & - \\
\hline
\end{tabular}

NEPR, northern East Pacific Rise; SEPR, southern East Pacific Rise.

belong to the same biogeographical province and share the same numerically dominant species, although macrofaunal diversity was lower at NEPR sites (Van Dover, 2003). The macrofaunal assemblages of young $(<6$ y) and old $(>8 \mathrm{y})$ mussel beds could also be distinguished by multivariate analysis (Van Dover, 2003; Dreyer et al., 2005).

This paper presents a study of the meiofauna of NEPR and SEPR mussel beds to complement the investigations of their macrofauna. The aims of this study are: (1) to describe the meiofaunal composition of NEPR and SEPR vent mussel beds, enabling comparison with other chemosynthetic and non-chemosynthetic deep-sea habitats where possible; and (2) to determine the composition of assemblages of the dominant meiofaunal taxon, the nematodes, comparing patterns of assemblage composition among sites spanning 27 degrees of latitude along the ridge axis, expanding on initial results reported from the NEPR by Flint et al. (2006).

\section{MATERIALS AND METHODS}

Study sites

Three mussel beds were sampled between $9^{\circ} 49^{\prime} \mathrm{N}$ and $9^{\circ} 51^{\prime} \mathrm{N}$ in November 1999 (Van Dover, 2003). Biovent, the northernmost bed in this study, predates a 1991 eruption event that resulted in local extinction of vent fauna and was at least $8 \mathrm{y}$ old at the time of sampling. East Wall and Train Station are situated $0.8 \mathrm{~km}$ and $2.5 \mathrm{~km}$ south of Biovent (Figure 1). Both mussel beds were established after the 1991 eruption event and were estimated to be 4 and 5 y old, respectively, at the time of sampling (Van Dover, 2003).

Four mussel beds were sampled between $17^{\circ} 24^{\prime} \mathrm{S}$ and $18^{\circ} 41^{\prime} \mathrm{S}$ in February 1999. Rehu Marka, the northernmost site sampled in this area, was estimated to be 10 to $16 \mathrm{y}$ old at the time of sampling, based on observations from previous expeditions in the area (Van Dover, 2002). At this site, beds of live mussels in areas of diffuse hydrothermal discharge up to $8^{\circ} \mathrm{C}$ above ambient temperature were interspersed among patches of empty mussel valves. Using similar observations, the Oasis site, $0.85 \mathrm{~km}$ south along the ridge axis from Rehu Marka, was estimated to be 6 y old and exhibited very little mussel mortality with vigorous diffuse flow $4.5^{\circ} \mathrm{C}$ above ambient (Van Dover, 2002).

Animal Farm lies $133 \mathrm{~km}$ further south (Figure 1) and occupies a lava flow at least 20 y old (Van Dover, 2002).
Hydrothermal activity at Animal Farm was waning at the time of sampling: high mussel mortality $(\sim 75 \%)$ was noted with no visible diffuse flow and no temperature anomalies greater than $0.1{ }^{\circ} \mathrm{C}$ above ambient (Van Dover, 2002). A single sample was also collected from Buddha's Place, $7.5 \mathrm{~km}$ south of Animal Farm along the ridge axis. No temperature measurements were made during sampling, but active venting was observed and little mussel mortality noted in contrast to Animal Farm. Location details, dates, dive numbers, indications of vent activity and age estimates are summarized for each site in Table 1.

\section{Sample collection and processing}

Samples were collected from the study sites using the submersible 'Alvin' in 1999. Discrete, quantitative samples were obtained using pot samplers (described in detail by Van Dover, 2002) consisting of an 11.35-1 kitchen stock pot lined with a $26 \mathrm{~cm}$ diameter Kevlar ${ }^{\circledR}$ drawstring bag. A rotating t-handle enables the submersible manipulator to close the drawstring bag. When placed over a mussel bed, the pot samples all fauna in a variable mussel volume beneath a constant area of $531 \mathrm{~cm}^{2}$. Once the drawstring is closed, each pot is placed in a quiver constructed from a plastic bucket on the submersible basket to prevent loss of any mussels. Samples were also collected using a Kevlar ${ }^{\circledR}$-lined scoop and stored in individual lidded boxes on the submersible basket. This technique risks possible loss of macrofaunal individuals through winnowing compared with the closed bag technique of the pot samplers. Consequently, scoop samples have previously been included in analyses of macrofaunal species richness but excluded from multivariate analyses of macrofaunal composition (Van Dover \& Trask, 2000; Van Dover, 2002; Dorries \& Van Dover, 2003; Turnipseed et al., 2003; Van Dover, 2003; Dreyer et al., 2005). The abundance of nematodes per litre of mussel volume, however, is actually greater in scoop samples than pot samples, indicating that this meiofaunal taxon is resistant to any winnowing effect. Scoop samples have therefore been included in multivariate analysis of nematode species composition here.

On deck, mussels were washed three times in filtered seawater and washings passed through $62-\mu \mathrm{m}$ aperture sieves to retain the meiofaunal size fraction. The meiofauna were preserved in buffered $10 \%$ formalin and stored in $70 \%$ 
A

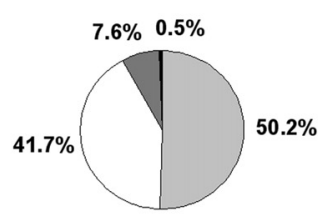

All mussel bed samples $(\mathbf{N}=19833)$

B

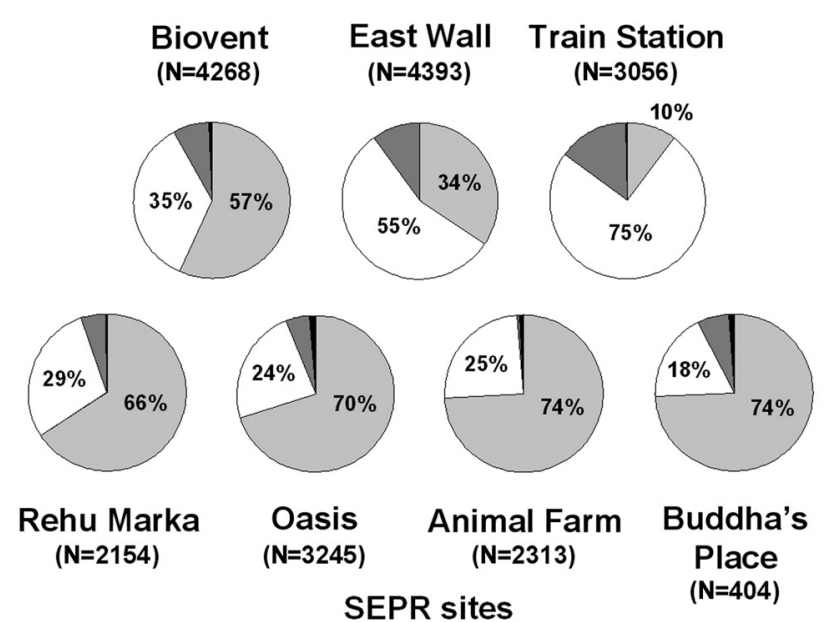

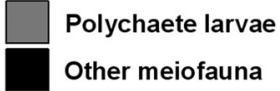

Other meiofauna

Figure 2. Composition of major meiofaunal taxa in mussel beds at hydrothermal vents on the East Pacific Rise. (A) Overall composition of all mussel bed samples; (B) composition of meiofauna at individual mussel bed sites. Details of other meiofaunal taxa present at low abundance are shown in Table 2.

EtOH. The volume of mussels collected in each sample was determined by immersing the mussels in a graduated container of water and measuring their displacement. In the laboratory, samples were individually washed with 45 $\mu \mathrm{m}$ filtered water into a $62-\mu \mathrm{m}$ sieve to remove the $\mathrm{EtOH}$. LUDOX $^{\mathrm{TM}}$ (specific gravity 1.16) was then washed over the material to remove the water and samples were centrifuged in LUDOX $^{\mathrm{TM}}$ for $5 \mathrm{~min}$ at $4000 \mathrm{rpm}$. Suspended material present after centrifugation was passed through a $62-\mu \mathrm{m}$ sieve, washed with $45 \mu \mathrm{m}$ filtered water and rinsed into a sample pot with $4 \%$ formalin. Decanted LUDOX ${ }^{\mathrm{TM}}$ was returned to the

centrifuge tube and remaining sediment resuspended before repeating the centrifugation and sieving. All samples were centrifuged in this way for 10 runs to extract the meiofauna from the fine sediment fraction. Each sample extract was split into eight parts using a sample splitter as described by Elmgrem (1973) and major taxa in splits were counted under a Leica MZ8 stereomicroscope. Percentages of major taxa, including nematodes and copepods, were recorded for each sample. The first 250 nematodes encountered were picked into an embryo dish of dehydrating solution $5 \%$ anhydrous glycerol, 5\% IMS alcohol and 90\% distilled water with phenol crystals to prevent fungal growth), which was placed in a desiccator for at least 24 hours.

Nematodes were mounted for identification on microscope slides in glycerol sealed by a ring of paraffin wax with glass beads supporting the coverslip. These slides were examined using an Olympus $\mathrm{BH} 2$ compound microscope at $100 \times$ magnification under oil immersion with Normarski differential interference contrast illumination. Specimens were identified to genus level using the pictorial keys of Platt \& Warwick (1983, 1988) and Warwick et al. (1998). Where morphological examination indicated more than one species per genus present, traditional nematode features were used to assign specimens to working species for subsequent analyses. Abundances of nematodes and other meiofauna were calculated per litre from volumes of mussels sampled. Although the volume sampled by each pot sampler was variable, abundances were also calculated per $10 \mathrm{~cm}^{2}$ from the $531 \mathrm{~cm}^{2}$ area of the sampler to enable comparison with studies in other environments (e.g. Soltwedel, 2000).

\section{Statistical analysis}

Nematode species richness and species density curves were calculated from sample effort data at each site using EstimateS (application available at http://viceroy.eeb.uconn. edu/estimates), employing 100 randomizations without replacement to randomize the data and eliminate the effect of sample order. Effort was considered as cumulative number of individuals sampled for species richness and cumulative mussel volume sampled for species density.

Shannon-Wiener diversity indices $\left(\mathrm{H}^{\prime}\right)$ based on natural logarithms were calculated for nematodes at each site using PRIMER v. 5 (PRIMER-E Ltd, Plymouth, UK). H' provides a comparative measure of diversity, combining both species richness and equitability. To compare equitability alone, Pielou's evenness $\left(J^{\prime}\right)$ values were also calculated using

Table 2. Summary of minor meiofaunal groups (<1\% total meiofaunal abundance) present in mussel beds on the East Pacific Rise.

\begin{tabular}{|c|c|c|c|c|c|}
\hline Site & Gastropod larvae & Acari & Foraminifera & Ostracoda & Turbellaria \\
\hline Biovent & + & + & & & + \\
\hline East Wall & + & & & & \\
\hline Train Station & & + & & & \\
\hline Rehu Marka & & + & & & \\
\hline Oasis & & + & + & + & \\
\hline Animal Farm & + & & + & + & \\
\hline Buddha's Place & + & & & & \\
\hline
\end{tabular}




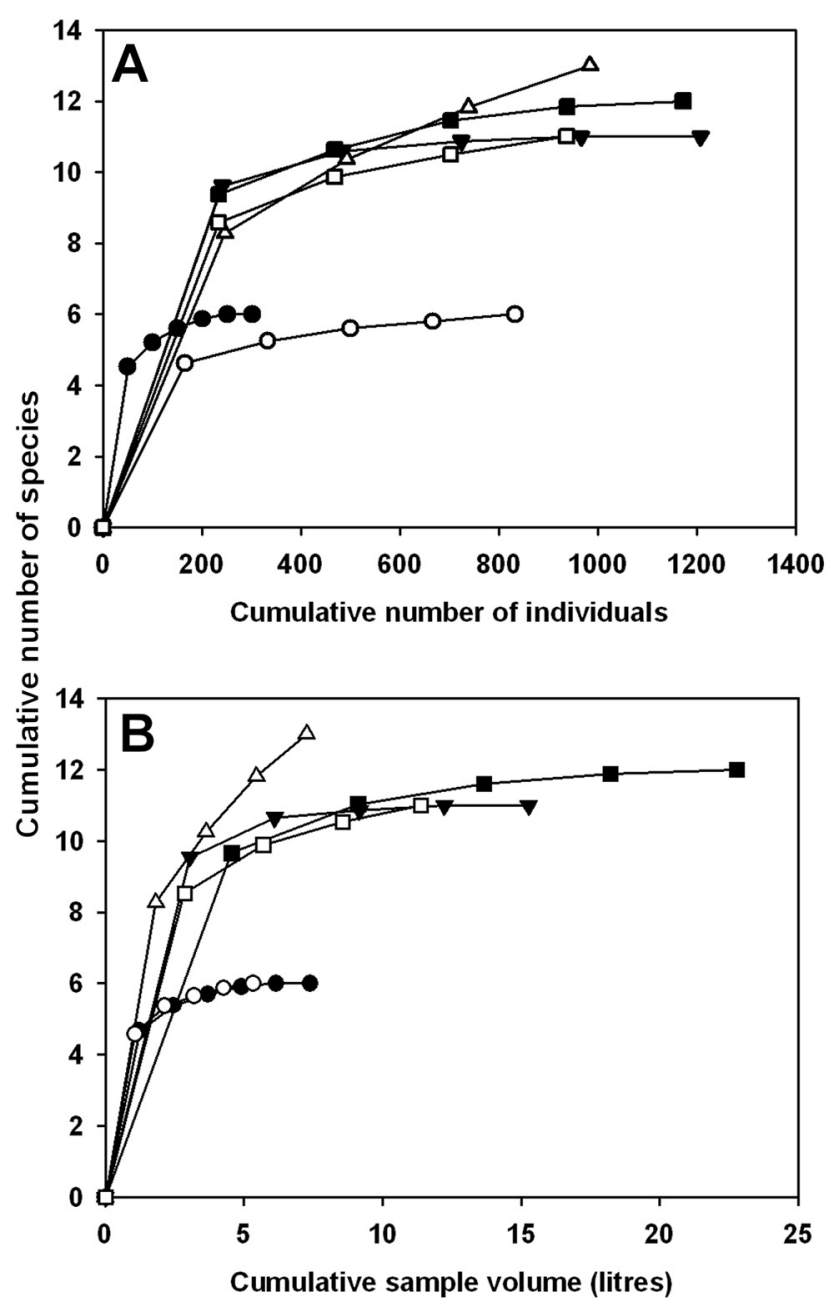

Figure 3. Sample-based species effort curves for nematodes from mussel beds on the East Pacific Rise. (A) Species richness: effort based on cumulative number of individuals; (B) species density: effort based on cumulative volume of mussels sampled (litres). Open circles, East Wall; closed circles, Train Station; closed triangles, Biovent; open squares, Rehu Marka; closed squares, Oasis; open triangles, Animal Farm.

PRIMER. J' provides a measure of equitability in the distribution of abundance among species. The graphical methods of $k$-dominance plots and Lorenz curves were also employed to examine rank abundance profiles of nematode species at each site. To produce $k$-dominance curves, cumulative ranked abundances were plotted against species rank for each site. The most elevated curve in such plots exhibits the lowest diversity (Lambshead et al., 1983). To compare dominance separately from number of species, species rank was rescaled from 0-100 (relative species rank) to produce Lorenz curves.

The structure of nematode assemblages in each sample was compared by multivariate analysis using PRIMER v. 5. A similarity matrix was constructed by applying the Bray-Curtis similarity index to fourth-root transformed nematode abundance data. Fourth-root transformation was employed to ensure even contributions of mid- and lowranking species, given the patterns of dominance revealed by the $k$-dominance plots and Lorenz curves. Hierarchical agglomerative cluster analysis was then performed on this similarity matrix using group-average linkage to produce a dendrogram based on Bray-Curtis similarity values. Nonmetric multidimensional scaling was also applied to the similarity matrix to produce a two-dimensional ordination of the samples, using ten random initial orientations to minimize the stress function.

\section{RESULTS}

\section{Composition of meiofauna in vent mussel beds}

Overall, nematodes dominated the meiofauna of hydrothermal vent mussel beds sampled on the East Pacific Rise in this study (9951 out of 19,833 individuals examined). Copepods were the second most abundant meiofaunal group, followed by polychaete larvae (Figure 2A). Other meiofaunal groups contributed $<1 \%$ of total meiofaunal abundance and the taxa present in this category are summarized for each site in Table 2.

The order of abundance exhibited in the samples overall (nematodes $>$ copepods $>$ polychaete larvae) was found at the majority of sites, apart from East Wall and Train Station (Figure 2B). Copepods were the numerically dominant meiofauna at these two sites and polychaete larvae were more abundant than nematodes at Train Station (451 compared with 312 out of 3056 individuals examined). The percentage ratio of nematodes to copepods was higher at SEPR sites compared with those on the NEPR (Figure 2B).

\section{Identity and occurrence of nematode species}

Seventeen nematode species from 14 genera in 11 families were identified in the samples (Table 3). Species richness and species density curves (Figure 3) indicate lower species richness at Train Station and East Wall compared with other sites. The Monhysteridae were the most abundant family at all sites except Animal Farm. Two species of Thalassomonhystera were found at all the sites, with Thalassomonhystera species A distinguished from Thalassomonhystera species B by its shorter length, conical tail shape and simple minute buccal cavity. Thalassomonhystera species A was the most abundant nematode at all sites except Animal Farm and Train Station. Thalassomonhystera species B was generally present at lower abundance, except at Animal Farm and Train Station. A single species of Geomonhystera was also present at all sites except Animal Farm and was the most abundant nematode species at Train Station.

A single species of the Anticomidae (Anticoma sp.) was present at all sites and was the most abundant nematode at Animal Farm. The Chromadoridae were also represented at all sites by Chromadorita species A, which was distinguished from a second species of the genus by the presence of cuticle punctuation with a distinctly ornate pattern of lateral differentiation, a weak oesophageal bulb and in the males, the presence of nine horseshoe shaped pre-cloacal supplements. Chromadorita species B has a less complex cuticle, a more distinct oesophageal bulb and no pre-cloacal supplements. Chromadorita species B was present at all sites except Train Station and East Wall, as was a species of the Draconematidae (Cephalochaetosoma sp.) and a species of the Cyatholaimidae (Paracanthoncus sp.). 


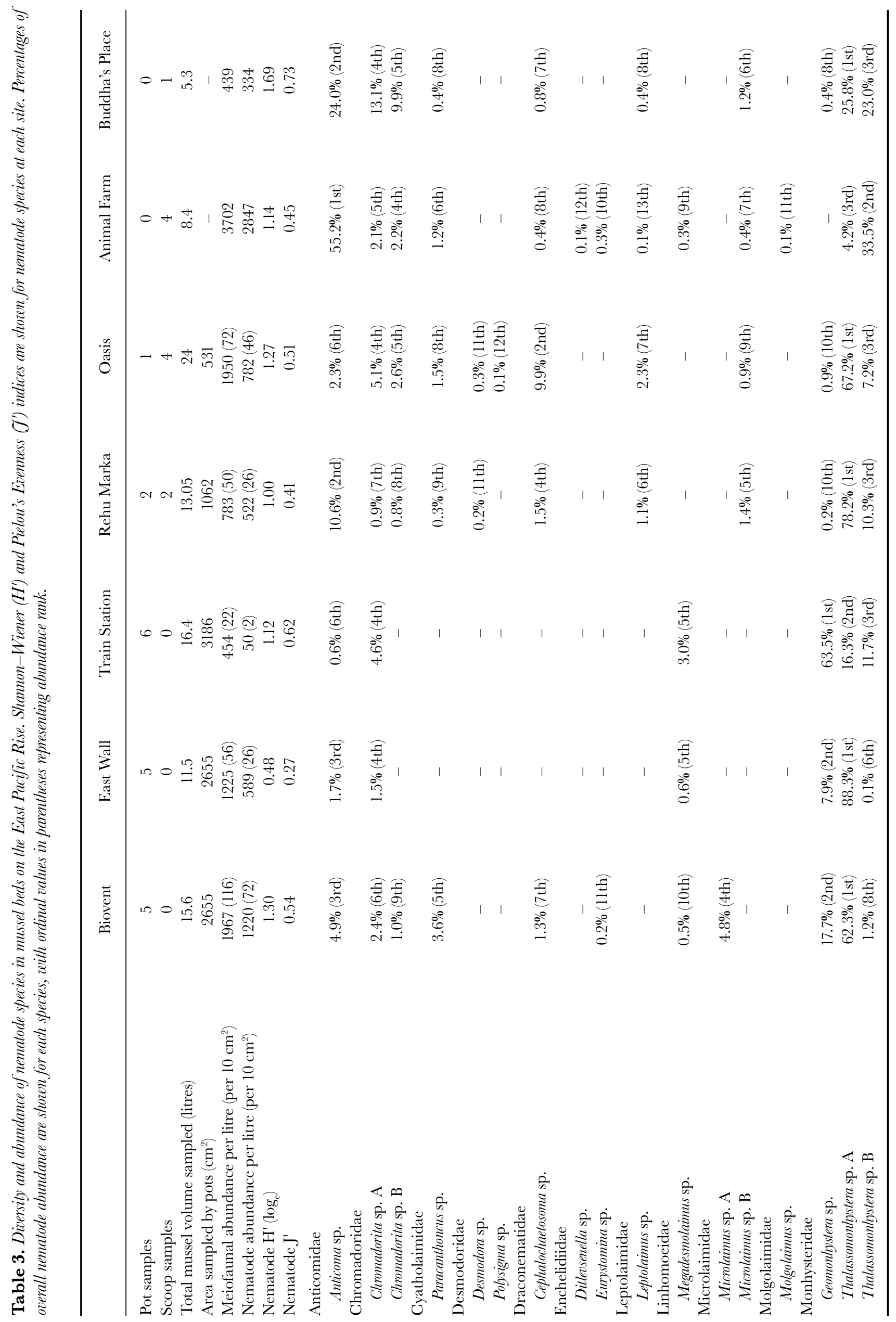




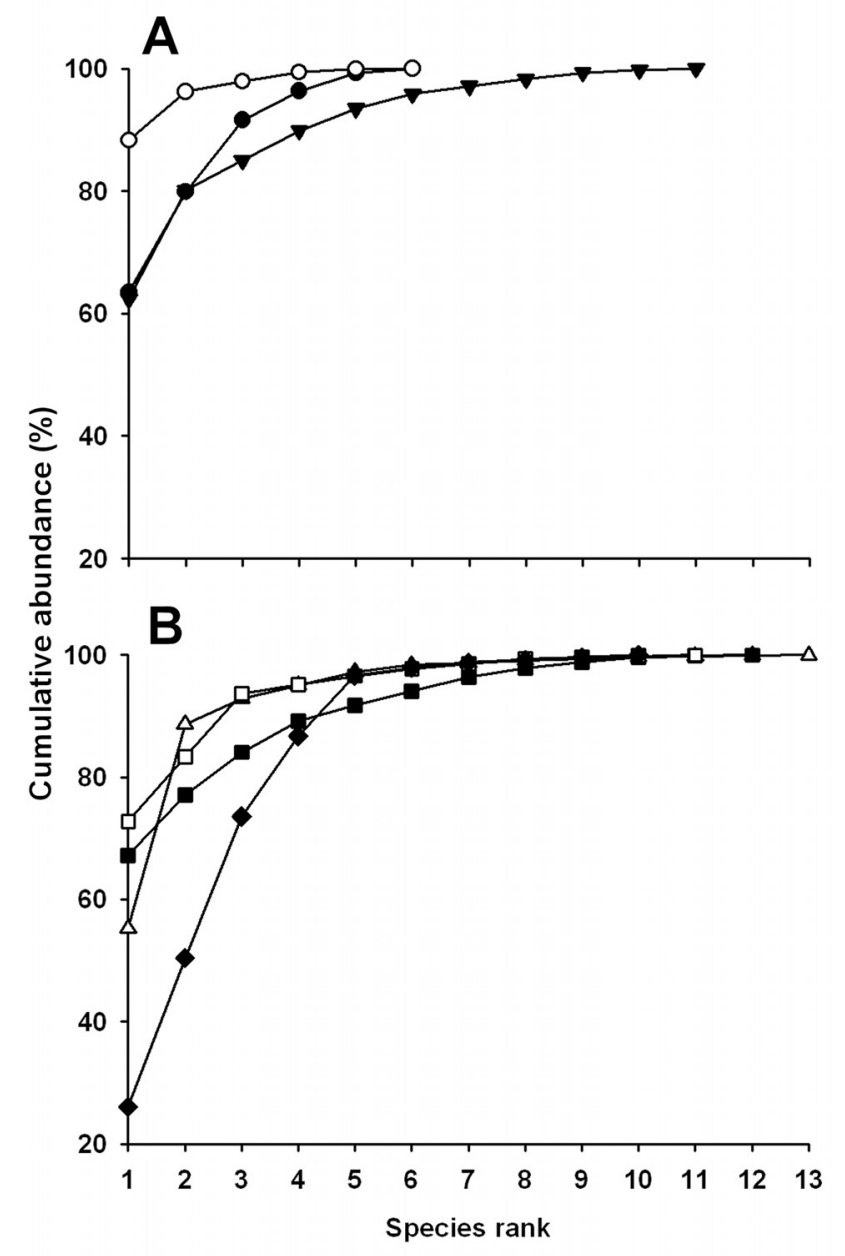

Figure 4. $k$-dominance plots (cumulative \% abundance vs species rank) for nematode species at mussel beds on the East Pacific Rise. (A) Northern East Pacific Rise (open circles, East Wall; closed circles, Train Station; closed triangles, Biovent); (B) southern East Pacific Rise (open squares, Rehu Marka; closed squares, Oasis; open triangles, Animal Farm; closed diamonds, Buddha's Place).

Two species of Microlaimidae were distinguished in the samples on the basis of copulatory spicule length and complexity. Microlaimus species A had longer spicules and a shorter, more angular gubernacular apophysis. Microlaimus species B has a longer gubernacular apophysis of a blunt appearance and shorter spicules. Microlaimus species A was only found at Biovent, while Microlaimus species B was restricted to the southern EPR sites. One species of the Leptolaimidae (Leptolaimus sp.) was also only found at southern EPR sites. The Linhomoeidae were represented by a single species (Megadesmolaimus sp.) at the northern EPR sites and Animal Farm. The Enchelidiidae and Desmodoridae were each represented by two species of different genera in very low abundances at only one or two sites. A single species of Molgolaimidae was found in low abundance at Animal Farm.

\section{Diversity and rank abundance profiles of nematode assemblages}

$\mathrm{H}^{\prime}$ values indicate that the nematode assemblage at East Wall was the least diverse, followed by Rehu Marka, Animal Farm, Oasis, Biovent, Train Station and Buddha's Place

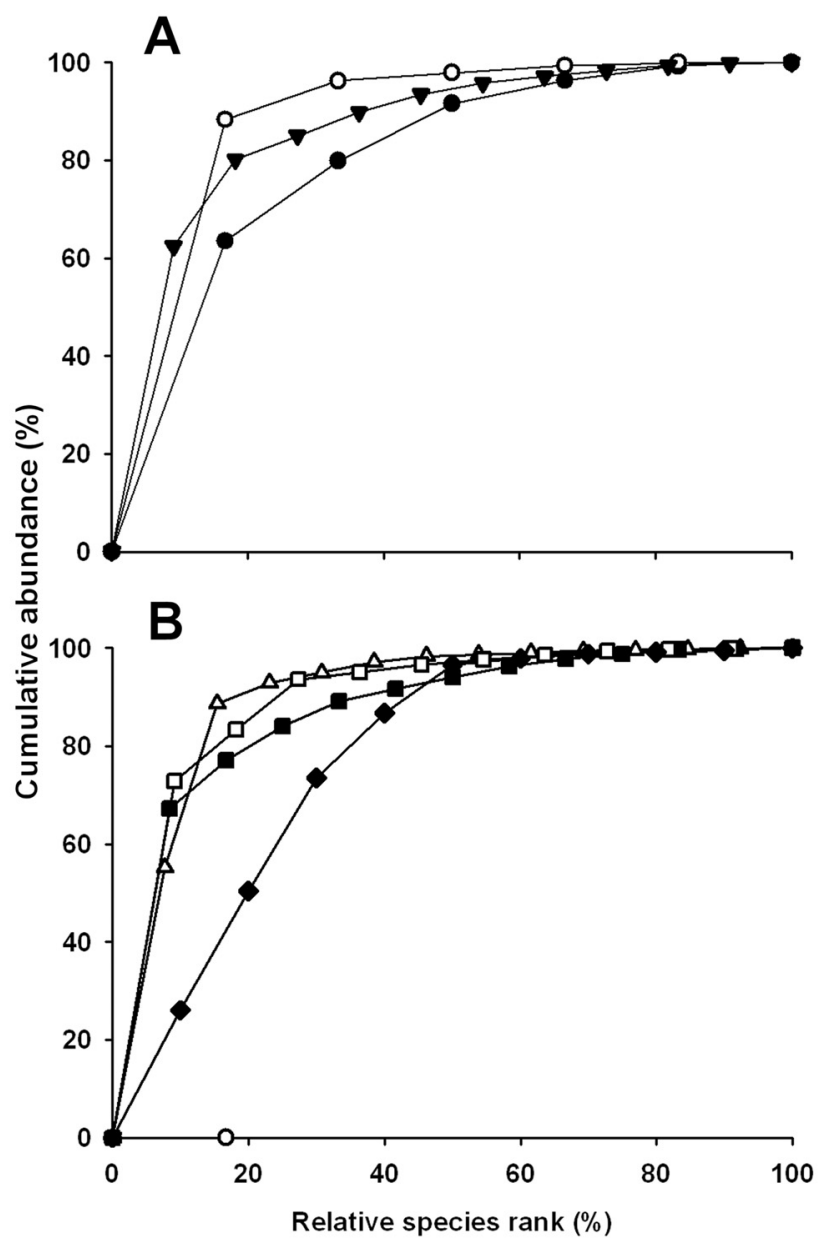

Figure 5. Lorenz curves (cumulative \% abundance vs relative $\%$ species rank) for nematode species at mussel beds on the East Pacific Rise. (A) Northern East Pacific Rise (open circles, East Wall; closed circles, Train Station; closed triangles, Biovent); (B) southern East Pacific Rise (open squares, Rehu Marka; closed squares, Oasis; open triangles, Animal Farm; closed diamonds, Buddha's Place).

(Table 3). As Train Station exhibited the same reduced species richness as East Wall compared with other sites, however, the variation in $\mathrm{H}^{\prime}$ values clearly reflects differences in evenness in addition to differences in species richness. Pielou's evenness values (Table 3 ) indicate that the least equitable distribution of abundance among nematode species occurred at East Wall and sites were ordered as follows in increasing Pielou's evenness values: East Wall $<$ Rehu Marka $<$ Animal Farm $<$ Oasis $<$ Biovent $<$ Train Station $<$ Buddha's Place. The most abundant species at East Wall accounted for $88 \%$ of total nematode abundance, compared with $63 \%$ and $64 \%$ at neighbouring sites Train Station and Biovent on the NEPR (Figure 4A). Among SEPR sites, the numerically dominant species at Rehu Marka comprised 73\% of the total nematode abundance, compared with $67 \%$ at Oasis, 55\% at Animal Farm and 26\% at Buddha's Place (Figure 4B).

In general, species ranked second or lower in terms of abundance at each site, each contributed less than $20 \%$ of the overall nematode abundance. There were exceptions to this distribution pattern, however, at Buddha's Place and Animal Farm: the second and third most abundant species 

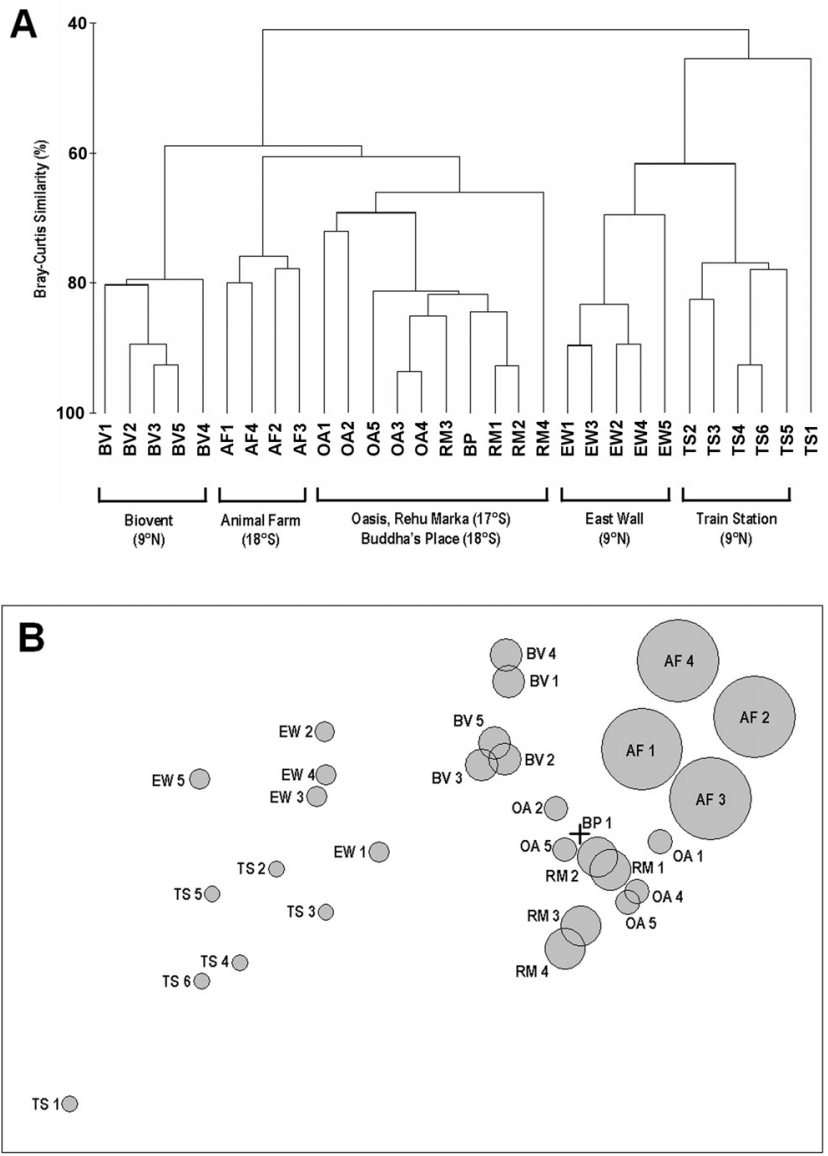

Figure 6. Multivariate analyses of nematode species assemblages at mussel beds on the East Pacific Rise. (A) Dendrogram from hierarchical agglomerative clustering of Bray-Curtis similarity of forth-root transformed abundance data using group-average linkage; (B) ordination from non-metric multidimensional scaling of Bray-Curtis similarity values (stress of ordination: 0.11 ). Size of bubbles overlaid on each sample represent estimated mussel bed age (Train Station, 4 years; Animal Farm, 20 years; no age estimate available for Buddha's Place).

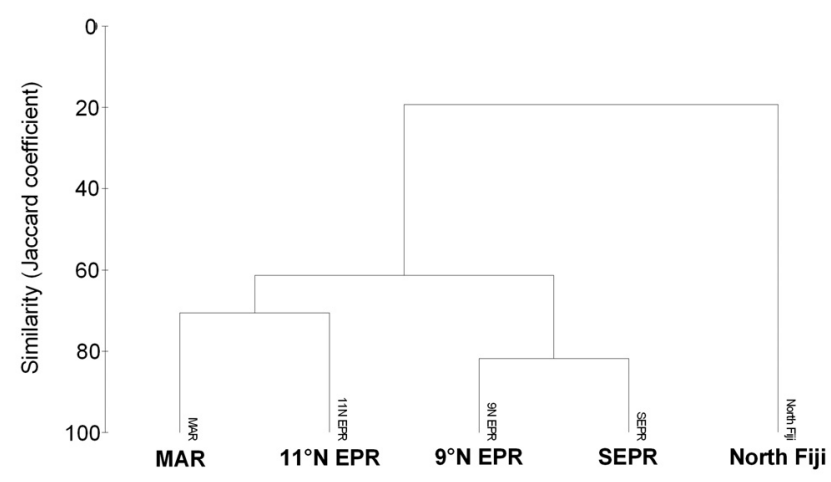

Figure 7. Dendrogram of similarity (expressed as Jaccard coefficient) in presence/absence of nematode genera in this study and others at hydrothermal vents. $9^{\circ} \mathrm{N}$ and SEPR, this study; MAR and $11^{\circ} \mathrm{N}$ EPR, Zekely et al. (2006a); North Fiji, Vanreusel et al. (1997).

at Buddha's Place contributed $24 \%$ and $23 \%$ to the total nematode abundance respectively, while the second most abundant species at Animal Farm contributed 33\% to the
Table 4. Summary of nematode genera reported at hydrothermal vents. $17-18^{\circ} \mathrm{S}$ and $9^{\circ} \mathcal{N}$ EPR this study; $11^{\circ} \mathcal{N}$ EPR and MAR data from Zekely et al. (2006a); North Fiji Basin records from Vanreusel et al. (1997).

\begin{tabular}{|c|c|c|c|c|c|}
\hline Genus & $\begin{array}{c}17-18^{\circ} \mathrm{S} \\
\mathrm{EPR}\end{array}$ & $\begin{array}{l}9^{\circ} \mathrm{N} \\
\mathrm{EPR}\end{array}$ & $\begin{array}{l}11^{\circ} \mathrm{N} \\
\text { EPR }\end{array}$ & MAR & $\begin{array}{c}\text { North } \\
\text { Fiji } \\
\text { Basin }\end{array}$ \\
\hline Acantholaimus & & & & & + \\
\hline Actinonema & & & & & + \\
\hline Aegialoalaimus & & & & & + \\
\hline Anticoma & + & + & + & + & + \\
\hline Araeolaimus & & & & + & \\
\hline Axonolaimus & & & & & + \\
\hline Calomicrolaimus & & & & & + \\
\hline Cephalanticoma & & & & & + \\
\hline Cephalochaetosoma & + & + & & & \\
\hline Chromadorina & & & & & + \\
\hline Chromadorita & + & + & + & + & \\
\hline Daptonema & & & & & + \\
\hline Desmodora & + & & & & + \\
\hline Diplopeltula & & & & + & + \\
\hline Ditleysnella & + & & & & \\
\hline Euchromadora & & & & & + \\
\hline Eurystomina & + & + & & & \\
\hline Geomonhystera & + & + & & & \\
\hline Halalaimus & & & & & + \\
\hline Innocuanema & & & & & + \\
\hline Leptolaimus & + & & + & + & + \\
\hline Marylinnia & & & & & + \\
\hline Megadesmolaimus & + & + & + & + & \\
\hline Molgolaimus & + & + & & & + \\
\hline Monhystera & & & & & + \\
\hline Oncholaimus & & & & & + \\
\hline Paracanthoncus & + & + & + & & + \\
\hline Paralinhomoeus & & & + & & + \\
\hline Polysigma & & + & & & \\
\hline Prochromadora & & & & & + \\
\hline Prochromadorella & & & & & + \\
\hline Southerniella & & & & & + \\
\hline Sphaerolaimus & & & & & + \\
\hline Symplocostoma & & & & & + \\
\hline Syringolaimus & & & & & + \\
\hline Terschellingia & & & & & + \\
\hline Thalassomonhystera & + & + & + & + & \\
\hline Theristus & & & + & & \\
\hline Wieseria & & & & & + \\
\hline
\end{tabular}

total abundance (Figure 4B). Lorenz curves, where species rank is converted to relative rank on percentage scale, distinguished differences in dominance from differences in species richness among sites. Among NEPR sites, the curves show that East Wall exhibited the highest dominance (greatest area beneath the curve), followed by Biovent and Train Station (Figure 5A). Animal Farm exhibited the highest overall dominance among SEPR sites, followed by Rehu Marka, Oasis and Buddha's Place (Figure 5B). 


\section{Multivariate analysis of nematode assemblages}

Cluster analysis identified samples from individual sites as more similar to each other than samples from other sites, with the exception of Train Station sample 1 and some samples from Rehu Marka and Oasis (Figure 6A). Train Station sample 1 was collected from the edge of the mussel bed and exhibited very low nematode abundances (50 individuals per litre of mussel volume sampled). Two main clusters were produced at a Bray-Curtis similarity level of $62 \%$, separating East Wall and Train Station samples 2-6 from all the other samples. The nematode assemblage at Biovent was therefore identified as more similar to those of SEPR sites than neighbouring NEPR sites. Within the SEPR sites, Oasis was more similar to its closest geographical neighbour, Rehu Marka, than Animal Farm. The single sample from Buddha's Place, however, was more similar to samples from Rehu Marka than Animal Farm, despite Animal Farm being the closest neighbouring site in this study.

A two-dimensional ordination of the samples by nonmetric multidimensional scaling (Figure 6B) confirms the similarity patterns of cluster analysis, with East Wall samples and Train Station samples separated from the other sites. Estimates of mussel bed age superimposed as bubbles on the ordination indicate a general cline in this parameter across the ordination (Figure 6B), while no such pattern was apparent from temperature measurements at each site.

\section{DISCUSSION}

\section{Diversity and abundance of mussel bed meiofauna}

Overall, the meiofauna of vent mussel beds examined in this study are dominated by nematodes (Figure 2), similar to soft-sediment deep-sea benthos at comparable depth (Soltwedel, 2000). Dominance by nematodes has also been observed in other chemosynthetic environments such as the Håkon Mosby mud volcano (Soltwedel et al., 2005). The percentage ratio of copepods in the samples overall is higher than that in sediments from non-chemosynthetic areas at similar depths, however, as is the percentage of polychaete larvae (Soltwedel, 2000). Foraminifera, rather than copepods, were the second most abundant group recorded at the Håkon Mosby mud volcano, which hosted a generally richer meiofauna than surrounding areas with a greater relative contribution of less abundant taxa (Soltwedel et al., 2005; Van Gaever et al., 2006). This contrasts with the very low abundance and diversity of other meiofaunal taxa in the samples from vent mussel beds examined here (Figure 2; Table 2).

The variable percentage ratio of copepods to nematodes found in this study is consistent with previous studies of other vent environments. Zekely et al. (2006a) recorded dominance by nematodes in mussel bed samples from the Mid Atlantic Ridge, but dominance by copepods in samples from $11^{\circ} \mathrm{N}$ on the East Pacific Rise. Dinet et al. (1988) examined the meiofauna from washings of vent macrofauna (vestimentiferans, alvinellid polychaetes and vesicomyid clams) from $21^{\circ} \mathrm{N}$ on the EPR, reporting a composition of $60 \%$ copepods and $35 \%$ nematodes, unlike the higher proportion of nematodes in the present study. Dinet et al. (1988) also recorded a meiofauna in scoops of hydrothermal sediments, however, that consisted of $65 \%$ nematodes and $13 \%$ copepods, more similar to the meiofaunal composition found at SEPR mussel beds here (Figure 2).

Vanreusel et al. (1997) examined grabs from vents in the North Fiji Basin that contained Bathymodiolus mussels, though at lower abundance (maximum 20 mussels in a grab of volume $0.6 \mathrm{~m}^{3}$ ) than mussel beds here and occupying more sedimented substrata. The meiofauna of these mussel beds exhibited high dominance by nematodes, which comprised $96 \%$ of meiofauna in the grab containing the greatest density of mussels (Vanreusel et al., 1997), assumed to be most comparable to the samples examined here. Copepods were also present in the sample, but at a much lower percentage ratio than our EPR mussel beds. Differences in meiofaunal composition among our mussel beds (Figure 2) and that sampled at $11^{\circ} \mathrm{N}$ on the EPR by Zekely et al. (2006a) indicate that site-specific variation can also occur within a region.

While nematodes were the numerically dominant meiofaunal taxon at the majority of sites in this study, copepods were dominant at East Wall and Train Station (Figure 2), which were the youngest mussel beds at the time of sampling (Table 1). Adopting a chronoseres approach therefore suggests that copepods may be the initial dominant meiofaunal colonists of vent mussel beds, with a general increase in the percentage ratio of nematodes to copepods over time (Figure 2). Oasis, however, is estimated to be marginally younger than Biovent, yet exhibited a higher percentage ratio of nematodes, similar to the other SEPR sites examined. An alternative possibility is therefore that a lower percentage ratio of nematodes to copepods may be a regional feature of NEPR mussel beds. Further studies of other NEPR mussel beds should confirm or refute this possibility.

Overall meiofaunal abundances in this study, expressed as individuals per litre of mussel volume sampled, are generally higher than those found by Zekely et al. (2006a) in mussel beds at $11^{\circ} \mathrm{N}$ on the East Pacific Rise and the Mid Atlantic Ridge (MAR: 560 to 631 ind $\mathrm{l}^{-1} ; 11^{\circ} \mathrm{N}$ EPR: 476 to 634 ind $\mathrm{l}^{-1}$; three replicates at each location. This study: 439 to 3702 ind $\mathrm{l}^{-1}$, based on 25 samples across seven locations). Quantitative studies of deep-sea meiofauna are traditionally based on sediment core samples and abundances expressed as number of individuals per $10 \mathrm{~cm}^{2}$ of core area, with depths of sediment examined varying from $1 \mathrm{~cm}$ to $5 \mathrm{~cm}$ or deeper. Direct comparison of such studies with the abundance values from the quantitative pot samples used in this study is therefore difficult. To enable such comparison, however, meiofaunal abundances have been expressed as individuals per $10 \mathrm{~cm}^{2}$ based on the $531 \mathrm{~cm}^{2}$ area of the pot sampler (Table 3), although it must be noted that the pot sampler collects a variable volume of mussels beneath that area. But assuming that this measure of sampling area is comparable with other studies, the abundance of meiofauna in vent mussel beds (Table 3) is the same order of magnitude as those found in deep-sea sediments at similar depths, though among the exceptional lower range of such studies (Vincx et al., 1994; Soltwedel, 2000). This appears to contrast with studies of cold seeps and mud volcanoes that exhibit elevated meiofaunal abundances compared with non-chemosynthetic 
sites nearby (Shirayama \& Ohta, 1990; Buck \& Barry, 1998; Robinson et al., 2004; Soltwedel et al., 2005; Van Gaever et al., 2006).

\section{Composition of nematode assemblages}

The nematode assemblages sampled at vent mussel beds in this study exhibited very low species richness compared with the soft-sediment deep-sea benthos (Lambshead \& Boucher, 2005), a feature also seen in vent mega- and macrofauna (Tunnicliffe, 1991; Van Dover, 2002). Species accumulation and species density curves (Figure 3) confirm that the majority of abundant nematode species are likely to have been sampled at each site, apart from Animal Farm, where the curves did not approach asymptotes within the sampling effort of this study. Animal Farm was estimated to be the oldest site at the time of sampling, with waning hydrothermal conditions (Table 1). East Wall and Train Station, in contrast, exhibited lower nematode species richness than other sites (Figure 3A) and were estimated to be the youngest mussel beds (Table 1).

All families and genera of nematodes identified in the samples from vent mussel beds in this study are known from non-hydrothermal environments, consistent with previous studies (Dinet et al., 1988; Vanreusel et al., 1997) and suggesting a lower taxonomic level of endemicity for nematodes compared with mega- and macrofauna at vents. Eleven of the 14 nematode genera in mussel bed samples exhibited a species to genus ratio of 1 . This preponderance of monospecific nematode genera was also noted in samples from North Fïi Basin examined by Vanreusel et al. (1997), in contrast to much higher species to genera ratios in reference samples of deep-sea sediments on the ridge flanks. Zekely et al. (2006a) also report monospecific nematode genera in mussel bed samples from the Mid Atlantic Ridge and $11^{\circ} \mathrm{N}$ on the East Pacific Rise.

Many of the species present in the samples appear to be new, however, suggesting possible endemicity to vent environments at the species level. Thalassomonhystera species $\mathrm{A}$ and the Geomonhystera species in this study resemble those recently described by Zekely et al. (2006b). The draconematid species Cephalochaetosoma sp. was similar to specimens of the same genus described from vents on the East Pacific Rise (Decraemer \& Gourbault, 1997), the genus Cephalochaetosoma having originally been described from abyssal depths near Mindanao Island in the Philippines (Kito, 1983). All of the species recorded by Zekely et al. (2006a) are similarly reported to be new to science. Other species in the samples will therefore be subject to further taxonomic investigation and new species formally described.

The three most abundant nematode species contributed more than $70 \%$ of the total nematode abundance at each site, apart from Buddha's Place where only a single sample was collected (Figure 3). The nematode assemblages of North Fiji vents similarly exhibit high dominance (>80\%) by a minority of species present (Vanreusel et al., 1997) and Jensen (1986) reported 90\% dominance by a single species of nematode at a brine seep in the north-western Gulf of Mexico. Van Gaever et al. (2006) record $>98 \%$ numerical dominance by a single species of Geomonhystera in sulphidic microbial mat sediments at the Håkon Mosby mud volcano. These results therefore suggest that high dominance by a minority of species among those present may be a general feature of nematode assemblages in sulphidic environments, similar to the distribution of abundance seen in mega- and macrofauna (Tunnicliffe, 1991; Van Dover, 2002).

Thalassomonhystera species A was the most abundant species at five out of seven sites and the Monhysteridae were the numerically dominant family at all sites except Animal Farm, where their abundance was only exceeded by the Anticomidae (Table 3). A species of Thalassomonhystera was also the most abundant nematode in mussel beds at $11^{\circ} \mathrm{N}$, while another species of the same genus was most abundant in samples from the Mid Atlantic Ridge (Zekely et al., 2006a). This contrasts with previous studies at other vent sites: Molgolaimus was the dominant genus at hydrothermal sites in the North Fiji Basin (Vanreusel et al., 1997) and Dinet et al. (1988) reported dominance by the Microlaimidae in macrofaunal washings and hydrothermal sediments at $21^{\circ} \mathrm{N}$ on the East Pacific Rise.

All of the families reported on the East Pacific Rise by Dinet et al. (1988) were present at vent mussel beds in this study apart from the Epsilonematidae, although those specimens may have been misidentified Desmodoridae (Vanreuesel et al., 1997). Table 4 summarizes nematode genera found in common between this study and previous studies working to genus level at hydrothermal vents (Vanreusel et al., 1997; Zekely et al., 2006a). Six genera are shared between the sites studied here and samples from $11^{\circ} \mathrm{N}$ and five genera are also present on the Mid Atlantic Ridge (Zekely et al., 2006a). Whether the same species of these genera are present will require future investigation once formal descriptions of species are available. Six genera present in the mussel beds examined here were also present at North Fiji hydrothermal vents (Vanreusel et al., 1997), representing an overlap of 17\% of the genera found in total by the two studies. The higher generic richness of the North Fiji sites may be a consequence of the greater sediment cover at these sites compared with the bare-rock hosted mussel beds on the EPR and MAR. Calculating Jaccard coefficients from presence/absence records of nematode genera at different sites (Table 4) and performing cluster analysis by group-average linkage indicates greater similarity between nematode assemblages at MAR and EPR mussel beds than North Fiji Basin (Figure 7), consistent with the difference in habitat type between these sites.

Shannon-Wiener diversity indices calculated for nematode species at each site (0.48 to 1.69 ; Table 3$)$ were generally lower than that found by Zekely et al. (2006a) at $11^{\circ} \mathrm{N}$ on the $\operatorname{EPR}\left(\mathrm{H}^{\prime}=1.67\right)$ and more similar to that reported by those workers from the Mid Atlantic Ridge $\left(\mathrm{H}^{\prime}=1.02\right)$, although sampling effort was greater in the study presented here. As species richness was higher at each site in this study apart from East Wall and Train Station, these generally lower $\mathrm{H}^{\prime}$ values compared with $11^{\circ} \mathrm{N}$ may reflect a less even distribution of abundance. This is confirmed by comparison of Pielou's evenness values, which range from 0.27 to 0.73 in this study, compared with 0.76 reported at $11^{\circ} \mathrm{N}$ by Zekely et al. (2006a). Vanreusel et al. (1997) report a Shannon-Wiener value of 3.4 for vent nematode species 
in the North Fiji Basin. This greater value reflects the higher nematode species richness found at the more sedimenthosted North Fiji vents by those workers.

Nematode abundances at all sites in this study except Train Station were greater than those found at $11^{\circ} \mathrm{N}$ by Zekely et al. (2006a). Using abundances expressed as individuals per litre of mussel volume sampled for direct comparison between studies, Zekely et al. (2006a) found 112 ind $\mathrm{l}^{-1}$ at $11^{\circ} \mathrm{N}$, compared with 334 to 2847 ind $\mathrm{l}^{-1}$ at sites here (Table 3). Train Station, however, exhibited an overall nematode abundance of 50 ind $\mathrm{l}^{-1}$. Zekely et al. (2006a) also recorded

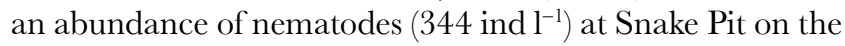
Mid Atlantic Ridge more comparable to most of the sites studied here. Nematode abundances expressed as individuals per $10 \mathrm{~cm}^{2}$ of area sampled by the pot sampler (2 to 72 individuals $10 \mathrm{~cm}^{-2}$; Table 3 ) appear to be at least an order of magnitude lower, however, than nematode abundances per $10 \mathrm{~cm}^{2}$ of sediment sampled in other deep-sea habitats (e.g. Stoetart et al., 2002), including cold seeps (Olu et al., 1997) and the Håkon Mosby mud volcano (Soltwedel et al., 2005; Van Gaever et al., 2006).

Low abundances of nematodes have been reported at a whale fall in the Santa Cruz basin, however (Debenham et al., 2004). Nematode abundance was elevated at $30 \mathrm{~m}$ from the whale carcass but decreased to very low numbers close to it, similar to those recorded here (12 to 641 individuals $10 \mathrm{~cm}^{2}$; Debenham et al., 2004). Debenham et al. (2004) propose that competition or predation from the enhanced macrofauna associated with the organic enrichment of the whale fall may suppress nematode abundances. Zekely et al. (2006a) propose the same possible explanation for low nematode abundances in vent mussel beds, noting the abundance of the predatory polychaete Ophryotrocha akessoni among mussel bed macrofauna as a possible control on nematode abundance. Similarities in abundance between pot samples from mussel beds and sediment cores must be treated with caution, however, given the assumptions required to make quantitative comparisons.

Sixteen nematode species were present at SEPR sites in this study and 11 species present at the NEPR sites. The NEPR nematode assemblages in this study may therefore be considered a subset of SEPR assemblages, as only one species (Microlaimus sp. A) was found at an NEPR site but not at any SEPR sites. This feature has also been noted among the macrofauna at the same sites by Van Dover (2002), who proposed a single biogeographic province extending for more than 30 degrees of latitude along the EPR from $13^{\circ} \mathrm{N}$ to $18^{\circ} \mathrm{S}$. Generic similarity of nematode assemblages is also apparent between $11^{\circ} \mathrm{N}$ (Zekely et al., 2006a) and the sites examined here. However, similarity in the composition of nematode assemblages between sites studied here does not reflect their geographical proximity (Figure 6A). This feature is also apparent in the generic comparisons of assemblages in this study with sites further afield (Figure 7). Within this study, cluster analysis identifies Train Station and East Wall as most similar to each other, but Biovent is more similar to SEPR sites than its NEPR neighbours. Although East Wall and Train Station displayed contrasting distributions of abundance (Figure 4A), both sites exhibited lower species richness than other sites (Figure 3A). East Wall and Train Station were also distinguished from other sites by a dominance of copepods (Figure 2).

Ordination by multidimensional scaling also distinguishes East Wall and Train Station from other mussel beds (Figure 6B). Superimposing estimated mussel bed ages on this ordination shows that nematode assemblages of the youngest and oldest mussel beds have the greatest separation in ordination space. Macrofaunal assemblages of the younger $(<6 \mathrm{y})$ sites could similarly be distinguished by multivariate analysis from those of the older $(>8 \mathrm{y})$ mussel beds (Van Dover, 2003; Dreyer et al., 2005). The nematode assemblages of the youngest sites (East Wall: 4 y; Train Station: 5 y) contained the fewest species (6 species each), but mussel beds older than 6 y contained similar numbers of nematode species (10 to 12 species; Table 3 ). The mussel bed at $11^{\circ} \mathrm{N}$ studied by Zekely et al. (2006a) similarly contained nine nematode species and was estimated to be $14 \mathrm{y}$ old at the time of sampling (Dreyer et al., 2005).

Mussel beds and the assemblages that they host may take time to establish, with mussels acting as a habitat engineer species. The lower nematode species richness in the youngest mussel beds in this study could be a consequence of this process. Nematodes do not have a planktonic life history phase, which may also account for the higher proportion of copepods at the youngest mussel beds, if copepods possess greater dispersal capabilities (Armonies, 1988). If many of the nematode species are endemic to vent environments, then colonization of new mussel beds must take place from nearby hydrothermal habitats. Nematodes may be present in other habitats such as tubeworm clumps within a vent field (Gollner et al., 2006), but ultimately dispersal must take place between vent sites and the same species are present over 27 degrees of latitude in this study. Jensen (1986) proposed that nematodes disperse in near-bottom currents to explain the occurrence of four species over 90 degrees of latitude in the deep East Atlantic. Future studies of the meiofauna of mussel beds further afield will determine whether nematodes and other meiofauna exhibit biogeographic patterns at vents on the same or greater scales than macro- and megafauna.

The authors thank the Captain and crew of the RV 'Atlantis' and the pilots and technicians of DSV 'Alvin' for their excellent support in collecting samples. P. Tyler (National Oceanography Centre, Southampton) is also thanked for providing laboratory facilities. This research is supported by a studentship from the National Oceanography Centre, Southampton, to H.C. Flint and a grant from the National Science Foundation (Biological Oceanography) to C.L. Van Dover.

\section{REFERENCES}

Armonies, W., 1988. Active emergence of meiofauna from intertidal sediment. Marine Ecology Progress Series, 43, 151-159.

Buck, K.R. \& Barry, J.P., 1998. Monterey Bay cold seep infauna: quantitative comparison of bacterial mat meiofauna with nonseep control sites. Cahiers de Biologie Marine, 39, 333-335.

Debenham, N.J., Lambshead, P.D.J., Ferrero, T.J. \& Smith, G.R., 2004. The impact of whale falls on nematode abundance in the deep sea. Deep-Sea Research I, 51, 701-706.

Decraemer, W. \& Gourbault, N., 1997. Deep-sea nematodes (Nemata, Prochaetosomatinae): new taxa from hydrothermal vents and a polymetallic nodule formation of the Pacific (East Pacific Rise; North Fiji and Lau Basins; Clarion-Clipperton fracture zone). Zoologica Scripta, 26, 1-12. 
Dinet, A., Grassle, F. \& Tunnicliffe, V., 1988. Premieres observations sur la meiofaune des sites hydrothermaux de la dorsale Est-Pacifique (Guaymas, $21^{\circ} \mathrm{N}$ ) et de l'Explorer Ridge. Oceanologica Acta, 85, 7-14.

Dorries, M.B. \& Van Dover, C.L., 2003. Higher-taxon richness as a surrogate for species richness in chemosynthetic communities. Deep-Sea Research I, 50, 749-755.

Dreyer, J.C., Knick, K.E., Flickinger, W.B. \& Van Dover, C.L., 2005. Development of macrofaunal community structure in mussel beds on the northern East Pacific Rise. Marine Ecology Progress Series, 302, 121-134.

Elmgrem, R., 1973. Methods of sampling sublittoral soft-bottomed meiofauna. Oikos, 15, 112-120.

Flint, H.C., Copley, J.T.P., Ferrero, T.J. \& Van Dover, C.L., 2006. Patterns of nematode diversity at hydrothermal vents on the East Pacific Rise. Cahiers de Biologie Marine, 47, 365-370.

Gollner, S., Zekely, J., Van Dover, C.L., Govenar, B., Le Bris, N. \& Bright, M., 2006. The benthic copepod community of tubeworm and mussel aggregations at the East Pacific Rise. Cahiers de Biologie Marine, 47, 397-402.

Humes, A.G., 1984. Benthospynus spiculifer new genus, new species (Copepoda, Siphonostomatoidea) associated with vestimentifera at a deep-sea geothermal vent off the coast of Washington. Canadian Fournal of Zoology, 62, 2594-2600.

Jensen, P., 1986. Nematode fauna in the sulphide-rich brine seep and adjacent bottoms of the East Flower Garden, NW Gulf of Mexico. IV. Ecological aspects. Marine Biology, 92, 489-503.

Kito, W., 1983. Deep-sea nematodes of Mindanao island, the Philippines. Annotationes Zoologicae Faponenses, 56, 27-41.

Lambshead, P.D.J. \& Boucher, G., 2005. Marine nematode deepsea biodiversity-hyperdiverse or hype? Journal of Biogeography, 30, 475-485.

Lambshead, P.D.J., Platt, H.M. \& Shaw, K.M., 1983. The detection of differences among assemblages of marine benthic species based on an assessment of dominance and diversity. Fournal of Natural History, 17, 859-874.

Mare, M.F., 1942. A study of a marine benthic community with special reference to the microorganisms. Fournal of the Marine Biological Association of the United Kingdom, 25, 517-554.

Olu, K., Lance, S., Sibuet, M., Henry, P., Fiala-Médioni, A. \& Dinet, A., 1997. Cold seep communities as indicators of fluid expulsion patterns through mud volcanoes seaward of the Barbados accretionary prism. Deep-Sea Research I, 44, 811-841.

Platt, H.M. \& Warwick, R.M., 1983. Free-living marine nematodes. Part I. British Enoplids. Synopses of the British Fauna, vol. 28. Cambridge: Cambridge University Press.

Platt, H.M. \& Warwick, R.M., 1988. Free-living marine nematodes. Part II. British Chromadorids. Synopses of the British Fauna, vol. 38. Cambridge: Cambridge University Press.

Robinson, C.A., Bernhard, J.M., Levin, L.A., Mendoza, G.F. \& Blanks, J.K., 2004. Surficial hydrocarbon seep infauna from the Blake Ridge (Atlantic Ocean, $2150 \mathrm{~m}$ ) and the Gulf of Mexico (690-2240 m). PSZNI: Marine Ecology, 25, 313-336.

SCOR Working Group 76, 1994. Suggested criteria for describing deep-sea benthic communities: the final report of SCOR Working Group 76. Progress in Oceanography, 34, 84-100.
Shirayama, Y. \& Ohta, S., 1990. Meiofauna in a cold-seep community off Hatsushima, Central Japan. Fournal of the Oceanography Society of Japan, 46, 118-124.

Soltwedel, T., 2000. Metazoan meiobenthos along continental margins: a review. Progress in Oceanography, 46, 59-84.

Soltwedel, T., Portnova, D., Kolar, I., Mokievsky, V. \& Schewe, I., 2005. The small-sized benthic biota of the Håkon Mosby Mud Volcano (SW Barents Sea slope). Fournal of Marine Systems, 55, 271-290.

Stoetart, K., Muthumbi, A. \& Heip, C., 2002. Size and shape of ocean margin nematodes: morphological diversity and depthrelated patterns. Marine Ecology Progress Series, 242, 179-193.

Tunnicliffe, V., 1991. The biology of hydrothermal vents - ecology and evolution. Oceanography and Marine Biology. Annual Review, 29, 319-407.

Turnipseed, M., Knick, K.E., Lipcius, R.N., Dreyer,J. \& Van Dover, C.L., 2003. Diversity in mussel beds at deep-sea hydrothermal vents and cold seeps. Ecology Letters, 6, 518-523.

Van Dover, C.L., 2002. Community structure of mussel beds at deep-sea hydrothermal vents. Marine Ecology Progress Series, 230, 137-158.

Van Dover, C.L., 2003. Variation in community structure within hydrothermal vent mussel beds of the East Pacific Rise. Marine Ecology Progress Series, 253, 55-66.

Van Dover, C.L. \& Trask, J., 2000. Diversity at deep-sea hydrothermal vent and intertidal mussel beds. Marine Ecology Progress Series, 195, 169-178.

Van Dover, C.L., German, G.R., Speer, K.G., Parson, L.M. \& Vrijenhoek, R.C., 2002. Evolutional and biogeography of deepsea vent and seep invertebrates. Science, New York, 295, 12531257.

Van Gaever, S., Moodley, L., Beer, D. de \& Vanreusel, A., 2006. Meiobenthos at the Arctic Håkon Mosby Mud Volcano, with a parental-caring nematode thriving in sulphide-rich sediments. Marine Ecology Progress Series, 321, 143-155.

Vanreusel, A., Van den Bossche, I. \& Thiermann, F., 1997. Free-living marine nematodes from hydrothermal sediments: similarities with communities from diverse reduced habitats. Marine Ecology Progress Series, 157, 207-219.

Vincx, M. et al., 1994. Meiobenthos of the deep northeast Atlantic. Advances in Marine Biology, 30, 1-88.

Warwick, R.M., Platt, H.M. \& Somerfield, P.J., 1998. Free-living marine nematodes. Part III. Monhysterids. Synopses of the British Fauna, vol. 53. Cambridge: Cambridge University Press.

Wigley, R.L. \& McIntyre, A.D., 1964. Some quantitative comparisons of offshore meiobenthos and macrobenthos south of Martha's Vineyard. Limnology and Oceanography, 9, 485-493.

Zekely, J., Van Dover, C.L., Nemeschkal, H.L. \& Bright, M., 2006a. Hydrothermal vent meiobenthos associated with mytilid mussel aggregations from the Mid-Atlantic Ridge and the East Pacific Rise. Deep-Sea Research I, 53, 1363-1378.

Zekely, J., Sørensen, V.M. \& Bright, M., 2006b. Three new nematode species (Monhysteridae) from deep-sea hydrothermal vents. Meiofauna Marina, 15, 25-42.

Submitted 10 October 2006. Accepted 3 May 2007. 